\title{
Notícia: X Congresso Internacional da Sociedade Italiana de Psicologia da Religião
}

\author{
Marta Helena de Freitas ${ }^{1}$ \\ Universidade Católica de Brasília
}

\section{News: X International Conference of the Italian Society for Psychology of Religion}

Nos dias 3 e 4 de setembro de 2004, em Verona - Itália, cidade de Romeu e Julieta, ocorreu o X Convegno Internazionale "Religione: Cultura, Mente e Cervello - Nuove prospettive in psicologia della religione", evento promovido pela Societá Italiana di Psicologia della Religione (SIPR), uma associação fundada em 1995, mas cujas raízes remontam à Società Italiana di Psicologia, fundada desde 1911, congregando cerca de 250 psicólogos italianos e em correspondência com numerosos centros acadêmicos e associações similares da Itália e de outros países.

O evento tem periodicidade bianual e este ano teve como objetivo o debate internacional sobre as novas tendências e perspectivas no estudo psicológico do comportamento religioso, em particular as relações entre cultura e neurobiologia, tendo contado com o apoio da Facoltà di Scienze della Formazione dell'Università di Verona, do Dipartimento di Psicologia dell'Università di Milano, e da Ordine degli Psicologi del Veneto.

A Comissão Científica e Organizadora do evento foi presidida pelo Prof. Dr. Mario Aletti, da Università Del Sacro Cuore, Milão, e atual presidente da Società Italiana di Psicologia della Religione, em Turin.

A programação científica esteve distribuída em sessões plenárias, no período matutino, e sessões grupais paralelas, no período vespertino, contando com a participação de ilustres convidados e de pesquisadores de vários outros países, dentre eles, quatro brasileiros, três dos quais apresentaram seus trabalhos de pesquisas na área.

Geraldo José de Paiva, professor da Universidade Federal de São Paulo (USP), apresentou um trabalho intitulado
Cultural and Neurobiological Complementary in Psychology of Religion. Marta Helena de Freitas, professora da Universidade Católica de Brasília, expôs sobre Religious Lapses of Psychology: Impact on the Student's Education. E José Rogério Machado de Paula, doutorando em Psicologia na USP, apresentou seu trabalho sobre Perception of Values among Brazilian Roman Catholic Seminarians.

Durante todo o evento, o entusiasmo foi compartilhado por todos os participantes. Afinal, as expectativas iniciais de traçar uma espécie de mapa do imenso território a que remete o tema do encontro foram mais do que alcançadas. Além disso, cada um levaria consigo, daqueles dois dias de intensas atividades e trocas intelectuais, a agradável atmosfera de amizade que as permearam o tempo todo.

Os interessados poderão encontrar o texto completo das conferências e os resumos dos trabalhos apresentados nas sessões paralelas no Abstract Book do evento, conforme referência completa ao final desta notícia.

\section{Referência}

Società Italiana di Psicologia della Religione \& Dipartimento di Psicologia e Antropologia Culturale dell'Università di Verona (Org.). (2004). X Convegno Internazionale. Religione: Cultura, mente e cervello. Nuove prospettive in psicologia della religione/Religion: Culture, mind and brain. New perspectives in psychology of religion. Pre-Atti / Abstracts Book. Verona, Itália.

1 Endereço: Rua 3/4 Sul, Lote 7/10, Bl. B, ap. 804, Águas Claras, 